\title{
Correction to: Risk of adverse perinatal outcomes after oocyte donation: a systematic review and meta-analysis
}

\author{
Jose Moreno-Sepulveda ${ }^{1,2} \cdot$ Miguel A. Checa ${ }^{1,3}$
}

Published online: 13 December 2019

(C) Springer Science+Business Media, LLC, part of Springer Nature 2019

Correction to: Journal of Assisted Reproduction and Genetics (2019) 36:2017-2037 https://doi.org/10.1007/s10815-019-01552-4

The original article unfortunately contained a mistake. the authors have written the wrong volume/issue/pages.

The correct reference is:

Kenny A. Rodriguez-Wallberg, Ann-Sofie Berger, Antonia Fagerberg, Jan I. Olofsson, Christina Scherman-Pukk, Pelle G. Lindqvist \& Josefine Nasiell (2019) Increased incidence of obstetric and perinatal complications in pregnancies achieved using donor oocytes and single embryo transfer in young and healthy women. A prospective hospital-based matched cohort study, Gynecological Endocrinology, 35:4, 314-319, DOI: $10.1080 / 09513590.2018 .1528577$

The online version of the original article can be found at https://oi.org/ 10.1007/s10815-019-01552-4

Jose Moreno-Sepulveda

jmorenos@gmail.com

Miguel A. Checa

macheca@parcdesalutmar.cat

1 Obstetrics and Gynecology Department, Parc de Salut Mar, Universitat Autonoma de Barcelona, Campus Universitario UAB, 08193 Bellaterra, Cerdanyola del Vallès, 08007 Barcelona, Spain

2 Clínica de la Mujer Medicina Reproductiva, Alejandro Navarrete, 2606 Viña del Mar, Chile

3 GRI-BCN, Barcelona Infertility Research Group, IMIM, Institut Hospital del Mar d'Investigacions Mèdiques, Carrer del Dr. Aiguader, 88, 08003 Barcelona, Spain 